\section{Cureus}

\title{
Metastatic Cholangiocarcinoma at Percutaneous Drain Site
}

\author{
Manoj K. Singh ${ }^{1}$, Manuel Rodriguez-Davalos ${ }^{2}$, David C. Wolf ${ }^{3}$, Marcelo E. Facciuto ${ }^{4}$ \\ 1. Medanta Liver Institute, Medanta The Medicity 2. Department of Surgery, Yale University School of \\ Medicine, New Haven, CT 3. Liver Transplant Center, Westchester Medical Center 4. Recanati Miller \\ Transplantation Institute, Mount Sinai School of Medicine
}

$\square$ Corresponding author: Manoj K. Singh, msingh78@gmail.com

Disclosures can be found in Additional Information at the end of the article

\section{Abstract}

We report the case of metastatic tumor recurrence at the chest wall exit site of percutaneous transhepatic biliary drainage (PTBD) catheter four months after surgical resection for cholangiocarcinoma. We discuss the risks and benefits of using PTBD catheters preoperatively in patients with planned major liver resection for malignancy.

Categories: Internal Medicine, General Surgery, Oncology

Keywords: catheter, cholangiocarcinoma, metastasis, percutaneous drain, chest wall, tumor

\section{Introduction}

Percutaneous transhepatic biliary drainage (PTBD) has become an established and effective method in the management of malignant obstructive jaundice, mainly in patients with unresectable disease. Although PTBD is considered safe, the procedure is not entirely free of complications including cholangitis, bile peritonitis, catheter dislocation, and hemorrhage [16]. Metastatic tumor seeding along the transhepatic biliary catheter is a very rare complication and until now there have been very few reported cases [7]. Therefore, the indications and approach for PTBD must be carefully considered. We present a case of metastasis along PTBD catheter tract in a patient after extended right hepatectomy for cholangiocarcinoma.

\section{Case Presentation}

A 55-year-old female presented with obstructive jaundice; her total bilirubin at time of admission was $13.1 \mathrm{mg} / \mathrm{dl}$. Radiologic work-up showed distended gallbladder with dilated intrahepatic ducts. ERCP showed a $2 \mathrm{~cm}$ irregular stricture at proximal common hepatic duct with dilated proximal ducts. Brush biopsy was sent which later confirmed the presence of malignant cells consistent with adenocarcinoma. An 8.5 French endoscopic internal biliary stent was placed. Upon further work-up, a computed tomography revealed a $4.1 \times 2.5 \times 1.8 \mathrm{~cm}$ lesion in segment $\mathrm{V}$ suspicious for cholangiocarcinoma, along with a distended abnormallooking gallbladder and intrahepatic biliary obstruction. In preparation for right trisegmentectomy, patient had ipsilateral portal vein embolization (PVE). Patient developed traumatic hemobilia during the procedure which may have led to biliary obstruction. Three days later, the patient developed symptoms of cholangitis which required a percutaneous transhepatic biliary drainage catheter placement. A puncture of the right biliary radicles was performed with a 21 gauge needle introduced from the right midaxillary approach. Cholangiogram showed occlusion of the right biliary radicles at the level of the porta hepatis despite the presence of the stent that was placed via ERCP. A catheter and a guidewire were manipulated into the common hepatic, bile duct and into the duodenum. Using Seldinger 


\section{Cureus}

method, a 12 French biliary drainage catheter was advanced into the duodenum.

Six weeks post-PVE, a triple phase CT (Figure 1) showed increase in future liver remnant (FLR). The patient underwent uneventful extended right hepatectomy and left hepatico-jejunostomy, and was discharged a week after. Pathology findings were consistent with infiltrating poorly differentiated cholangiocarcinoma arising in major bile duct; tumor size $5.5 \times 5.5 \mathrm{x} 4 \mathrm{~cm}$; tumor emboli seen in lymphatics, venules, peri and intraneural tissues. Proximal and distal bile duct margins were free of tumor; left periportal and portal lymph nodes were negative for tumor.

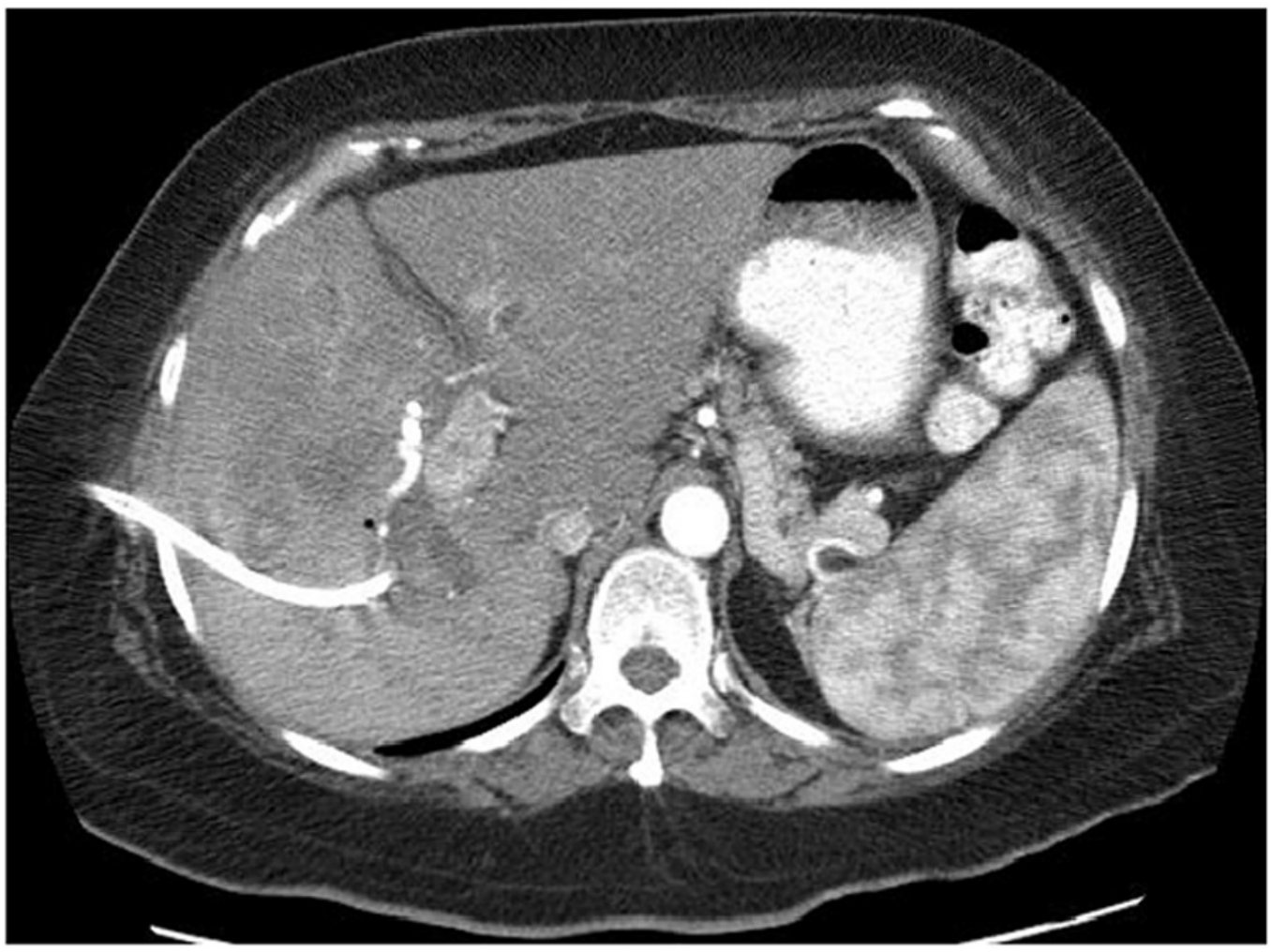

\section{FIGURE 1: CT March 07 before tharapy of the left paraaortic}

\section{tumor}

Four months later, the patient presented with recurrence nodule at the chest wall exit site (Figure 2). Biopsy of the chest wall lesion revealed malignant cells consistent with cholangiocarcinoma. The patient underwent chemotherapy and radiation with no response and died 10 months after surgery. 


\section{Cureus}

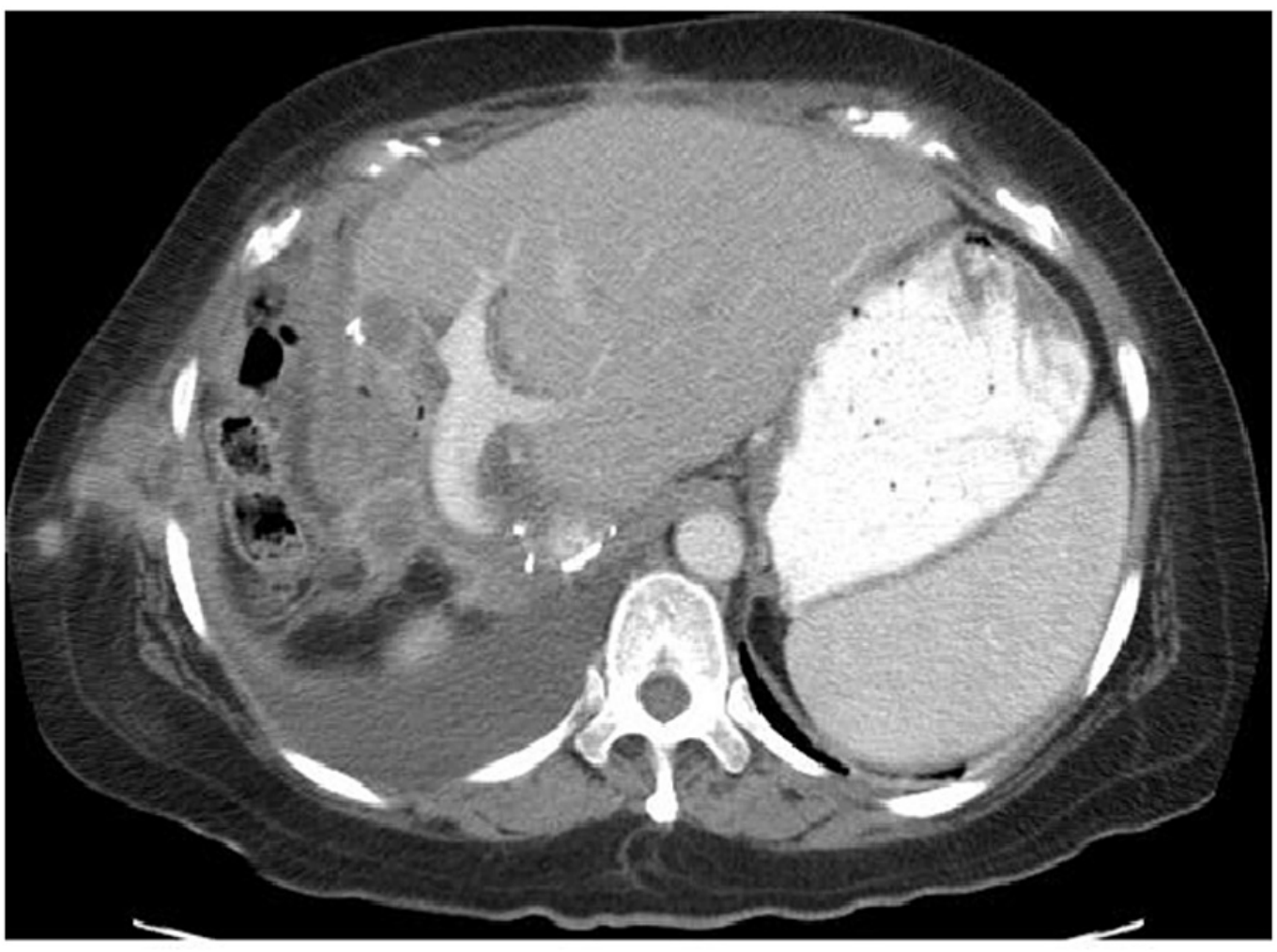

FIGURE 2: Right sided lung metastasis, segment 5

\section{Discussion}

The incidence of catheter tract implantation metastasis after PTBD has been reported to range from $0.6 \%-6 \%$ in patients with malignant biliary obstruction due to tumors of various origins [8-14]. Uesaka et al. [14] have reported that catheter tract implantation metastasis from hilar cholangiocarcinoma occurred more frequently in patients with well-differentiated tumors.

The routine use of preoperative PTBD for malignant obstructive jaundice remains controversial. Preoperative biliary drainage has been advocated before major hepatectomy to reduce postoperative infections and critical liver failure in jaundiced patients [15, 16-20], due to the potential adverse effects of biliary obstruction to liver physiology, including protein turnover [21] and reticuloendothelial function [22]. It is indicated in selected patients, such as severely malnourished or hypoalbuminic patients or those suffering from acute cholangitis or longstanding jaundice [23-25].

Several case series of liver resection in patients with obstructive jaundice from expert groups, with and without PTBD, reported identical mortality, morbidity and blood loss [19, 26-35]. Cherqui et al. [35] have reported increased transfusion requirement and postoperative complications, particularly bile leaks and subphrenic collections in jaundiced patients, but comparable to those reported in patients with biliary obstruction subjected to PTBD.

Prospective randomized studies have shown that routine preoperative PTBD lack clinical benefit $[24,36]$. The most common complications associated with PTBD are cholangitis, sepsis, hemorrhage, and bile leak with or without peritonitis with incidence varying from 5-10\% [2, 3, $25,25,37,38]$. Hochwald et al. [39] have shown increased postoperative infectious complications as result of preoperative biliary stenting in proximal cholangiocarcinoma. Povoski et al. [16] have shown that preoperative biliary drainage in patients undergoing 
pancreaticoduodenectomy is associated with increased incidence of postoperative complications, primarily infectious complications, intra-abdominal abscess and death.

Resection has long been recognized as the most effective therapy for hilar cholangiocarcinoma [40], but curative resection can be achieved only in a small minority, 28\% [41] of patients. Efforts to reduce the rate of surgical complications in this subset of patients is warranted to improve perioperative outcome.

\section{Conclusions}

In view of known risk of extrahepatic tumor spread, the use of routine biliary instrumentation and preoperative percutaneous biliary drainage should be avoided in patients with potentially resectable liver tumors.

\section{Additional Information}

\section{Disclosures}

Human subjects: All authors have confirmed that this study did not involve human participants or tissue. Conflicts of interest: In compliance with the ICMJE uniform disclosure form, all authors declare the following: Payment/services info: All authors have declared that no financial support was received from any organization for the submitted work. Financial relationships: All authors have declared that they have no financial relationships at present or within the previous three years with any organizations that might have an interest in the submitted work. Other relationships: All authors have declared that there are no other relationships or activities that could appear to have influenced the submitted work.

\section{References}

1. Molnar W, Stockum AE: Relief of obstructive jaundice through percutaneous transhepatic catheter-a new therapeutic method. Am J Roentgenol Radium Ther Nucl Med. 1974, 122:356357.

2. Nakayama T, Ikeda A, Okuda K: Percutaneous transhepatic drainage of the biliary tract:technique and results in 104 cases. Gastroenterology. 1978, 74:554-559.

3. Denning DA, Ellison EC, Carey LC: Preoperative percutaneous transhepatic biliary decompression lowers operative morbidity in patients with obstructive jaundice. Am J Surg. 1981, 141:61-65.

4. Mueller PR, van Sonnenberg E, Ferrucci JT Jr.: Percutaneous biliary drainage: technical and catheter related problems in 200 procedures. AJR Am J Roentgenol. 1982, 138:17-23.

5. Carrasco CH, Zornoza J, Bechtel WJ: Malignant biliary obstruction: complications of percutaneous biliary drainage. Radiology. 1984, 152:343-346.

6. Joseph PK, Bizer LS, Sprayregen SS, et al: Percutaneous transhepatic biliary drainage: results and complications in 81 patients. JAMA. 1986, 255:2763-2767.

7. Chapman WC, Sharp KW, Weaver F, Sawyers JL: Tumor seeding from percutaneous biliary catheters. Ann Surg. 1989, 209:708-713.

8. Sano T, Nimura Y, Hayakawa N, et al: Partial hepatectomy for metastatic seeding complicating pancreatoduodenectomy. Hepatogastroeneterology. 1997, 44:263-267.

9. Tersigni R, Rossi P,Bochicchio O, et al: Tumor extension along percutaneous transhepatic biliary drainage tracts. Eur J Radiol. 1986, 6:280-282.

10. Oleaga JA, Ring EJ, Freiman DB, et al: Extension of neoplasm along the tract of a transhepatic tube. AJR Am J Roentgenol. 1980, 135:841-842.

11. Shorvon PJ, Lueng JW, Corcoran M, et al: Cutaneous seeding of malignant tumors after insertion of percutaneous prosthesis for obstructive jaundice. Br J Surg. 1984, 71:694-695.

12. Kim WS, Barth KH, Zinner M: Seeding of pancreatic carcinoma along the transhepatic catheter tract. Radiology. 1982, 143:427-428.

13. Nimura Y, Kamiya J, Kondo S, et al: Aggressive preoperative management and extended 
surgery for hilar cholangiocarcinoma: Nagoya experience. J Hepatobiliary Pancreat Surg. 2000, 7:155-162.

14. Uesaka K, Kamiya J, Nagino M, et al: Treatment of recurrent cancer after surgery for biliary malignancies. Nihon Geka Gakkai Zasshi. 1999, 100:195-199.

15. McPherson GAD, Benjamin IS, Hodgson HJF, et al: Pre-operative percutaneous transhepatic biliary drainage: the results of a controlled trial. Br J Surg. 1984, 71:371-375.

16. Povoski SP, Karpeh MS, Conlon KC, et al: Association of preoperative biliary drainage with postoperative outcome following pancreaticoduodenectomy. Ann Surg. 1999, 230:131-142.

17. Takada T, Hanyu F, Kobayashi S, et al: Percutaneous transhepatic cholangial drainage : direct approach under fluoroscopic control. J Surg Oncol. 1976, 8:83-97.

18. Miyagawa S, Makuuchi M, Kawasaki S: Outcome of extended right hepatectomy after biliary drainage in hilar duct cancer. Arch Surg. 1995, 130:759-763.

19. Saleh MMA, Norregaard P, Jorgensen HL, et al: Preoperative endoscopic stent placement before pancreaticoduodenectomy: a metaanalysis of the effect on morbidity and mortality. Gastrointest Endosc. 2002, 56:529-534.

20. Sewnath ME, Karsten TM, Prins MH, et al: A meta-analysis on the efficacy of preoperative biliary drainage for tumors causing obstructive jaundice. Ann Surg. 2002, 236:17-27.

21. Lee E, Ross B, Haines J: The effect of experimental bile-duct obstruction on clinical biosynthetic functions of the liver. Br J Surg. 1972, 59:564-568.

22. Bailey M: Endotoxin, bile salts and renal function in obstructive jaundice . Br J Surg. 1976, 63:774-778.

23. Cutherell L, Warold HJ, Tegtmeyer CJ: Catheter tract seeding after percutaneous biliary drainage for pancreatic cancer. Cancer. 1986, 57:2057-2060.

24. Hatfield ARW, Tobias R, Terblanche J, et al: Preoperative external biliary drainage in obstructive jaundice. Lancet. 1982, 23:896-899.

25. Ishikawa Y, Oishi I, Miyai M, et al: Percutaneous transhepatic drainage: experience in 100 cases. J Clin Gastroenterol. 1980, 2:305-314.

26. Makuuchi M, Thai BL, Takayasu, et al: Preoperative portal embolization to increase safety major hepatectomy for hilar bile duct carcinoma: a preliminary report. Surgery. 1990, 107:521527.

27. Bismuth H, Nakache R, Diamond T: Management strategies in resection for hilar cholangiocarcinoma. Ann Surg. 1992, 215:31-38.

28. Vauthey JN, Blumgart LH: Recent advances in the management of cholangiocarcinomas . Semin Liver Dis. 1994, 14:109-114.

29. Nimura Y, Hayakawa N, Kamiya J, et al: Combined portal vein and liver resection for carcinoma of the biliary tract. Br J surg. 1991, 78:727-731.

30. Parc Y, Frileux P, Balladur P, et al: Surgical strategy for the management of hilar bile duct cancer. Br J Surg. 1997, 84:1675-1679.

31. Pichlmayr R, Weimann A, Klempnauer J, et al: Surgical treatment in proximal duct cancer: a single center experience. Ann Surg. 1996, 224:628-638.

32. Childs T, Hart M: Aggressive surgical therapy for Klatskin tumors . Am J Surg. 1993, 165:554557.

33. Madriaga JR, Iwatsuki S, Todo S, et al: Liver resection for hilar and peripheral cholangiocarcinomas: a study of 62 cases. Ann Surg. 1995, 130:270-276.

34. Ogura Y, Mizumoto R, Tabata M, et al: Surgical treatment of carcinoma of the hepatic duct confluence : analysis of 55 resected carcinomas. World J Surg. 1993, 17:85-93.

35. Cherqui D, Benoist S, Malassagne B, et al: Major liver resection for carcinoma in jaundiced patients without preoperative biliary drainage. Arch Surg. 2000, 135:302-308.

36. Pitt HA, Gomes AS, Lois JF, et al: Does preoperative biliary drainage reduce operative risk or increase hospital cost?. Ann Surg. 1985, 201:545-553.

37. Gunther RW, Schild H, Thelen M: Percutaneous transhepatic biliary drainage: experience with 311 procedures. Cardiovasc Intervent Radiol. 1988, 11:65-71.

38. Gazzaniga GM, Faggiono A, Bondanza G, et al: Percutaneous transhepatic biliary drainage twelve years experience. Hepatogastroenterology. 1990, 37:517-523.

39. Hochwald SN, Burke EC, Jarnagin WR, et al: Association of preoperative biliary stenting with increased postoperative infectious complications in proximal cholangiocarcinoma. Arch Surg. 1999, 134:261-266.

40. Launois B, Campion JP, Brissot P, et al: Carcinoma of the hepatic hilus. Surgical management 


\section{Cureus}

and the case for resection. Ann Surg. 1979, 190:151-157.

41. Jarnagin WR, Fong Y, DeMatteo RP, et al: Staging, resectability, and outcome in 225 patients with hilar cholangiocarcinoma. Ann Surg. 2001, 234:507-519. 